\title{
Reduction of Secondary Amides to Imines Catalysed by Schwartz's Reagent
}

\author{
Liam J. Donnelly*, Jean-Claude Berthet, Thibault Cantat ${ }^{*}$ \\ Université Paris-Saclay, CEA, CNRS, NIMBE, 91191 Gif-sur-Yvette, France. E-mail: \\ liam.donnelly@cea.fr, thibault.cantat@cea.fr
}

\begin{abstract}
The partial reduction of amides is a challenging transformation that must overcome the intrinsic stability of the amide bond, a ubiquitous motif in organic chemistry, and exhibit high chemoselective control. To address this challenge, we describe a zirconiumcatalysed synthesis of imines by the reductive deoxygenation of secondary amides. This reaction exploits the excellent chemoselectivity of Schwartz's reagent $\left(\mathrm{Cp}_{2} \mathrm{Zr}(\mathrm{H}) \mathrm{Cl}\right)$ to avoid overreduction to amine products and utilises $(\mathrm{EtO})_{3} \mathrm{SiH}$ as a mild stoichiometric reductant to enable catalyst turnover. The reaction generally proceeds with high yields (13 examples, 70 to $95 \%$ yield) and tolerates a variety of functional groups (alkene, ether, nitro, etc.). Stoichiometric mechanistic investigations suggest the regeneration of the active $[\mathrm{Zr}]-\mathrm{H}$ catalyst is achieved through the $\sigma$-bond metathesis of $\mathrm{Si}-\mathrm{H}$ and $\mathrm{Zr}-\mathrm{OR}$.
\end{abstract}

\section{Introduction}

Organic amides are prevalent in pharmaceutical, agrochemical and natural products as well as a variety of functional polymer materials. Therefore, methods to selectively reduce these functional groups could open new opportunities for late-stage functionalisation and post-polymerisation modification to access products that are difficult to synthesise by classical methods. ${ }^{1-3}$ However, the carboxamide bond is relatively inert to hydride addition requiring forcing conditions using strongly reducing stoichiometric reagents, such as $\mathrm{LiAlH}_{4}$, leading to narrow functional group tolerance. Several catalytic protocols with a variety of catalysts ( $\mathrm{Fe}, \mathrm{Ru}, \mathrm{La}, \mathrm{B}$, etc.) have been developed to enable the use of milder reducing agents (such as $\mathrm{H}_{2}$, hydrosilanes and hydroboranes) with the aim of improving the chemoselectivity of these transformations (Scheme 1A). However, upon reduction of the amide the corresponding imine derivative is initially formed and, because the imine derivative is more electrophilic than the amide, further reduction to the amine is observed for the majority of these protocols. ${ }^{1,4-5}$ The development of catalytic methodologies that avoid overreduction to the amine product and instead allow selective formation of the imine product, an important electrophilic synthon in organic chemistry, are highly valuable and can complement traditional methods for imine synthesis.

Charette and co-workers reported the direct conversion of secondary amides to imine derivatives using $\mathrm{Tf}_{2} \mathrm{O}$ as an activator and $\mathrm{Et}_{3} \mathrm{SiH}$ as the reductant. ${ }^{6-7}$ This powerful 
transformation offered exceptional functional group tolerance (e.g., nitrile, ester, aldehyde) and generally proceeded with high yields. However, the reaction requires the use of cryogenic temperatures and stoichiometric quantities of the air-sensitive and corrosive $\mathrm{Tf}_{2} \mathrm{O}$. Brookhart and co-workers reported the Ir-catalysed deoxygenation of secondary amides to imines or amines, depending on the equivalents of $\mathrm{Et}_{2} \mathrm{SiH}_{2}$ present in the reaction, using an $\operatorname{Ir}(\mathrm{I})$ catalyst $\left[\operatorname{Ir}(\mathrm{COE})_{2} \mathrm{Cl}\right]_{2}(\mathrm{COE}=$ cyclooctene $)$ (Scheme 1A). ${ }^{8} \mathrm{~A}$ similar protocol using Vaska's complex $\left(\operatorname{IrCl}(\mathrm{CO})\left(\mathrm{PPh}_{3}\right)\right)$ for the formation of enamines from tertiary amides bearing monosubstituted $\beta$-carbon atoms was reported by Nagashima and co-workers. ${ }^{9}$ Several groups have since expanded on these seminal reports to develop methods for the reductive functionalization of secondary and tertiary amides by addition of a variety of nucleophiles to the transiently formed imine derivatives. ${ }^{10-14}$

A) Current Methods for the Catalytic Reduction of Secondary Amides

Overreduction to amine:

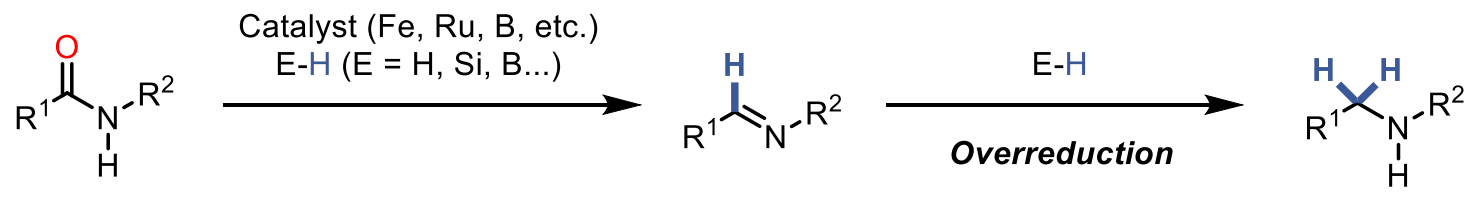

Brookhart et al, 2012:

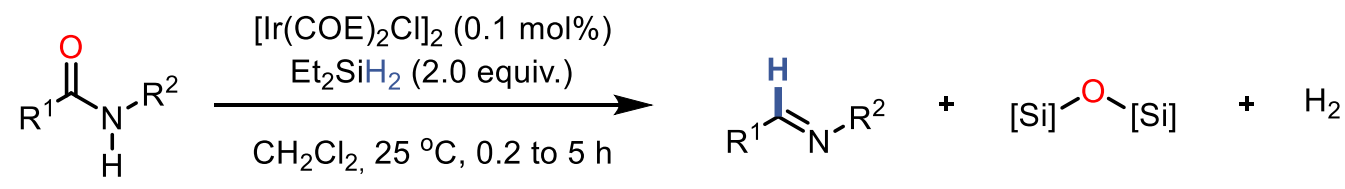

B) Stoichiometric Reduction of Secondary Amides using Zirconium

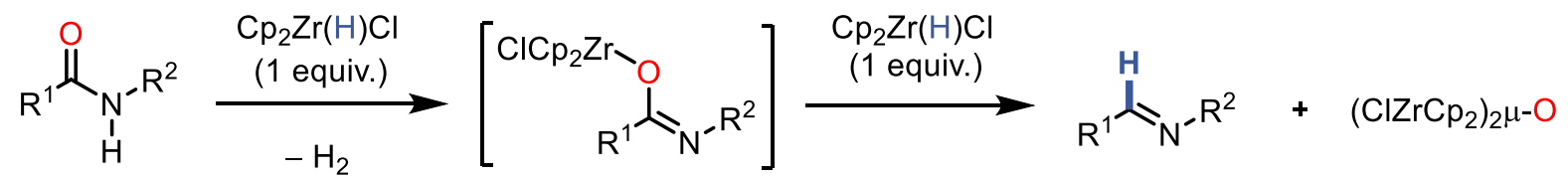

C) This work: Catalytic Reduction of Secondary Amides using Zirconium

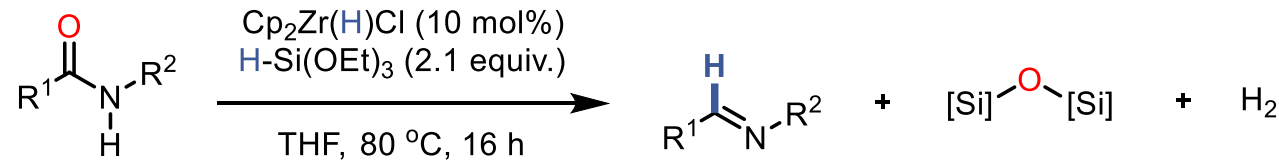

Scheme 1. The challenge of chemoselectivity in the catalytic reduction of amides to amines or imines.

Although these $\operatorname{Ir}(\mathrm{I})$ complexes are competent catalysts for the deoxygenation of amides, there is a desire to replace catalysts based on noble metals with more earth abundant metals. Ganem and Georg showed that the commercially available Schwartz 
reagent $\left(\mathrm{Cp}_{2} \mathrm{Zr}(\mathrm{H}) \mathrm{Cl}\right)(\mathbf{1})$ can reduce secondary amides to imines stoichiometrically with liberation of $\left(\mathrm{ClZrCp}_{2}\right)_{2} \mathrm{O}(2)$ as a byproduct (Scheme 1B). ${ }^{15-18}$ Very recently, Wu and coworkers reported the hydroboration of amides catalyzed by $\mathrm{Cp}_{2} \mathrm{ZrH}_{2}$, however, the final product is the corresponding amine rather than the imine. ${ }^{19}$ Complex 1 was shown to be an active, albeit sluggish, catalyst for this reaction. This result confirms the ability to regenerate $\mathrm{Zr}-\mathrm{H}$ from $\mathrm{Zr}$-OR using main group hydrides and enable catalyst turnover. Inspired by this work, we envisaged that hydrosilanes would be well poised to act as milder reductants to control the chemoselectivity of the amide reduction and stop at the imine product, ${ }^{20}$ in a similar fashion to our previous work on the reduction of ureas to formamidines. ${ }^{21}$ Herein, we report a practical and efficient protocol for the deoxygenation of secondary amides to imines using catalyst $\mathbf{1}$ and hydrosilanes (Scheme 1C). We also describe our preliminary studies aimed at elucidating the reaction mechanism.

\section{Results \& Discussion}

Initial conditions using catalyst $1(10 \mathrm{~mol} \%)$ in $\mathrm{C}_{6} \mathrm{D}_{6}$ at $60{ }^{\circ} \mathrm{C}$ for $16 \mathrm{~h}$ were applied to a screen of hydrosilanes (2.1 equiv.) for the reduction of $\mathrm{N}$-methylbenzamide $3 \mathbf{a}(\mathrm{ESI})$. The aryl- and alkylsilanes $\mathrm{Ph}_{2} \mathrm{SiH}_{2}, \mathrm{Ph}_{3} \mathrm{SiH}, \mathrm{Et}_{3} \mathrm{SiH}$ and $\mathrm{Et}_{2} \mathrm{SiH}_{2}$ only provided trace conversion to the imine product $4 \mathrm{a}$. The alkoxysilanes $\mathrm{Me}(\mathrm{EtO})_{2} \mathrm{SiH}$ and $(\mathrm{EtO})_{3} \mathrm{SiH}$ provided the imine as the major product $(82 \%$ and $86 \%)$ and the overreduced amine as the minor product (10\% and $7 \%)$. However, polymethylhydrosiloxane (PMHS) only provided trace yield of imine and tetramethyldisiloxane (TMDS) gave $14 \%$ conversion of the amide with an $11 \%$ yield of imine.<smiles>CNC(=O)c1ccccc1</smiles>

3a

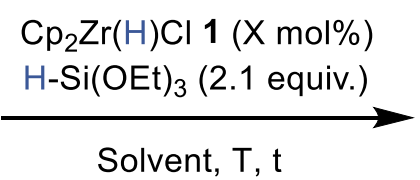

Solvent, $\mathrm{T}, \mathrm{t}$<smiles>CN=Cc1ccccc1</smiles>

$4 a$<smiles>CN(C)C(c1ccccc1)c1ccccc1</smiles>

[Si]

\begin{tabular}{|l|l|l|l|l|l|}
\hline Entry & $\mathrm{X}$ & Solvent & $\mathrm{T}\left({ }^{\circ} \mathrm{C}\right) / \mathrm{t}(\mathrm{h})$ & Conversion & $\begin{array}{l}\text { Yield } \\
(\mathbf{4 a} / 5 \mathbf{a})\end{array}$ \\
\hline 1 & 10 & $\mathrm{C}_{6} \mathrm{D}_{6}$ & $80 / 8$ & $>95 \%$ & $84 \% / 10 \%$ \\
\hline 2 & 10 & $\mathrm{THF}^{\mathrm{d}} \mathrm{d}_{8}$ & $80 / 8$ & $90 \%$ & $86 \% / 0 \%$ \\
\hline 3 & 10 & $\mathrm{CD}_{2} \mathrm{Cl}_{2}$ & $80 / 16$ & $52 \%$ & $39 \% / 13 \%$ \\
\hline 4 & 10 & $\mathrm{THF}_{8} \mathrm{~d}_{8}$ & $60 / 16$ & $68 \%$ & $68 \% / 0 \%$ \\
\hline 5 & 5 & $\mathrm{THF}_{8} \mathrm{~d}_{8}$ & $80 / 16$ & $88 \%$ & $85 \% / 6 \%$ \\
\hline 6 & 10 & $\mathrm{THF}_{8} \mathrm{~d}_{8}$ & $80 / 16$ & $>95 \%$ & $91 \% / 4 \%$ \\
\hline $7^{\mathrm{b}}$ & 10 & $\mathrm{THF}_{8} \mathrm{~d}_{8}$ & $80 / 16$ & $>95 \%$ & $>95 \% / 0 \%$ \\
\hline 8 & 0 & $\mathrm{THF}_{8} \mathrm{~d}_{8}$ & $80 / 16$ & $0 \%$ & $0 \% / 0 \%$ \\
\hline
\end{tabular}

Table 1. Optimisation of reaction conditions for the reduction of $\mathbf{3 a}$ to $\mathbf{4 a}$. aYield measured by ${ }^{1} \mathrm{H}$ NMR against mesitylene as an internal standard. ${ }^{b}$ Order of addition: add $[\mathrm{Zr}]$ before silane instead of adding [Zr] last. 
Further optimisation of this reaction was conducted using $(\mathrm{EtO})_{3} \mathrm{SiH}$ as the silane (Table 1). Switching solvents from $\mathrm{C}_{6} \mathrm{D}_{6}$ to THF- $\mathrm{d}_{8}$ and increasing the temperature to $80^{\circ} \mathrm{C}$ gave higher chemoselectivity for the imine 3 product over the corresponding amine 4 (Entries 1 and 2), however, the reaction in $\mathrm{CD}_{2} \mathrm{Cl}_{2}$ gave reduced yields and chemoselectivity (Entry 3). Running the reaction at $60^{\circ} \mathrm{C}$ gave a poorer yield even after an extended reaction time of $48 \mathrm{~h}$ (Entry 4). Reducing the catalyst loading to 5 mol\% also resulted in poorer yields and reduced chemoselectivity (Entry 5). Optimised conditions were established with $10 \mathrm{~mol} \%$ of the catalyst at $80^{\circ} \mathrm{C}$ for $16 \mathrm{~h}$ and changing the order of addition from adding the catalyst to adding the silane last appears to increase the chemoselectivity (Entries 6 and 7). The reaction does not proceed in the absence of 1 and only gives $<5 \%$ yield in the absence of silane (Entry 8 ).

With these optimised conditions in hand, we explored the substrate scope of this reaction focusing on substrates with secondary amide functionalities. By first varying the amine portion of the substrate, a variety of alkyl and aryl benzamides $\mathbf{3 a}-\mathbf{3 e}$ were tolerated under these conditions. The reaction does not appear to be sensitive to steric bulk on the amine portion, evidenced by the high yield for the conversion of $\mathrm{N}$ cyclohexylbenzamide $\mathbf{3 e}$ to the corresponding imine $\mathbf{4 e}$. Ether and furanyl functional groups were tolerated ( $\mathbf{3} \mathbf{f}$ and $\mathbf{3 g}$ ) and, interestingly, in the case of $\mathrm{N}$-allylbenzamide $3 \mathrm{~h}$ the terminal alkene was not reduced, leading to clean formation of the desired imine product $4 \mathrm{~h}$. Variation of the carbonyl portion of the substrates did not show a strong dependence on the electronics of $p$-substituted benzamides $\mathbf{3} \mathbf{i}-\mathbf{3 k}$ and the nitro group of $\mathbf{3 k}$ is not reduced under these conditions. The excellent yield for the $\mathrm{N}$ benzylisobutyramide $\mathbf{3 l}$ to the corresponding imine $\mathbf{4} \mathbf{I}$ shows that the reaction is not influenced by steric bulk on the carbonyl portion and the product does not tautomerise to the enamide under these conditions. 6-Chloro-2-oxindole $3 \mathrm{~m}$ could also be deoxygenated with this system to form the aromatised indole product $4 \mathrm{~m}$. Primary amine and terminal alkyne functional groups were not tolerated ( $3 n$ and 30) due to catalyst deactivation and observed competitive hydrosilylation to give a complex mixture of alkenyl products, ${ }^{22}$ respectively. 


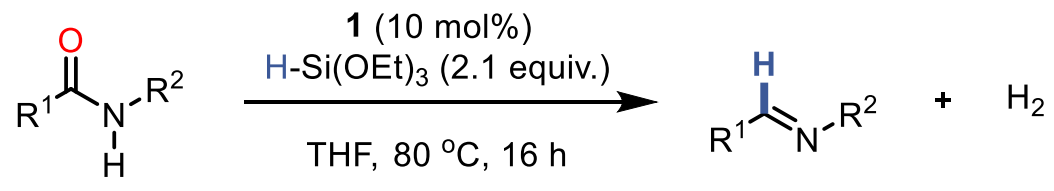

3

4<smiles>C/N=C/c1ccccc1</smiles><smiles>C(=N/Cc1ccccc1)\c1ccccc1</smiles><smiles>C(=Nc1ccccc1)c1ccccc1</smiles><smiles>CCCCCC=Nc1ccccc1</smiles>

$>95 \%, 4 a$<smiles>C(=N/C1CCCCC1)\c1ccccc1</smiles><smiles>COCCN=Cc1ccccc1</smiles><smiles>C(=N/c1ccco1)\c1ccccc1</smiles><smiles>C=CCN=Cc1ccccc1</smiles><smiles>COc1ccc(/C=N/Cc2ccccc2)cc1</smiles>

$89 \%, 4 i$<smiles>Brc1ccc(/C=N/Cc2ccccc2)cc1</smiles>

$92 \%, 4 j$<smiles>O=[N+]([O-])c1ccc(/C=N/Cc2ccccc2)cc1</smiles>

$91 \%, \mathbf{4 k}$<smiles>CC(C)/C=N/Cc1ccccc1</smiles>

$81 \%, 4 \mid$<smiles>Clc1ccc2cc[nH]c2c1</smiles>

$92 \%, 4 m$

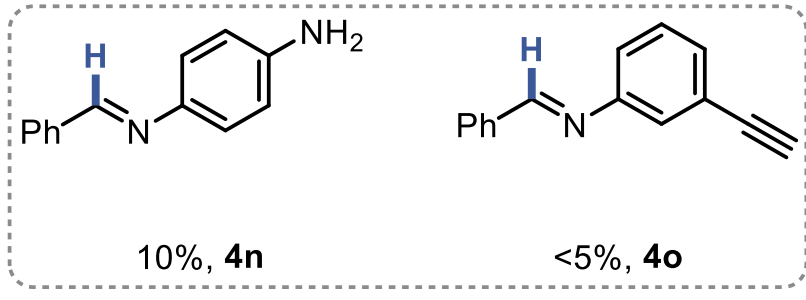

Unsuccessful substrates

Scheme 2. Substrate scope for the Zr-catalysed reduction of amides to imines. Yield measured by ${ }^{1} \mathrm{H}$ NMR against mesitylene as an internal standard, isolated yields in brackets.

During this study, we wished to gain further insight into the reaction mechanism through a series of stoichiometric reactions. We have already shown that the amide 3a does not react directly with (EtO) ${ }_{3} \mathrm{SiH}$ (Table 1, Entry 8), which suggests that 1 is the reactive hydride species. The reaction of $3 \mathbf{a}$ with 1 produced the corresponding imine $4 a$ in $47 \%$ yield with unreacted amide $3 a$ present after 15 mins at $25^{\circ} \mathrm{C}$ with elimination of $\mathrm{H}_{2}$ (Signal at $4.55 \mathrm{ppm}$ in the ${ }^{1} \mathrm{H}$ NMR spectrum) (Scheme $3 \mathrm{~A}$ ). In contrast to the analogous reaction with tertiary amides, the expected amidatozirconocene product $\mathbf{6 a}$ 
formed upon reaction of the amide with one equivalent of 1 was not observed. These results are consistent with the findings of Ganem and suggest initial deprotonation of the $\mathrm{N}-\mathrm{H}$ bond by one equivalent of $1,{ }^{15}$ followed by the rapid reaction of this intermediate with a second equivalent of $\mathbf{1}$ with concomitant formation of byproduct $\mathbf{2}$. Addition of $(\mathrm{EtO})_{3} \mathrm{SiH}$ (2 equiv.) did not result in any further conversion of the amide 3a or further reduction of the imine at $25^{\circ} \mathrm{C}$. However, heating to $80^{\circ} \mathrm{C}$ for $2 \mathrm{~h}$ resulted in full conversion of the amide $3 \mathbf{a}$ and $90 \%$ yield of the imine $\mathbf{4 a}$ with no observed formation of the corresponding amine product $5 \mathbf{a}$.

A)

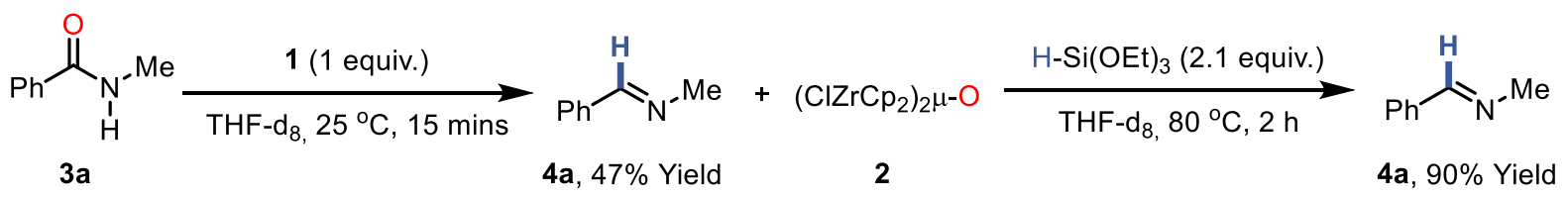

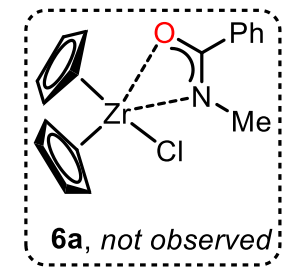

B)

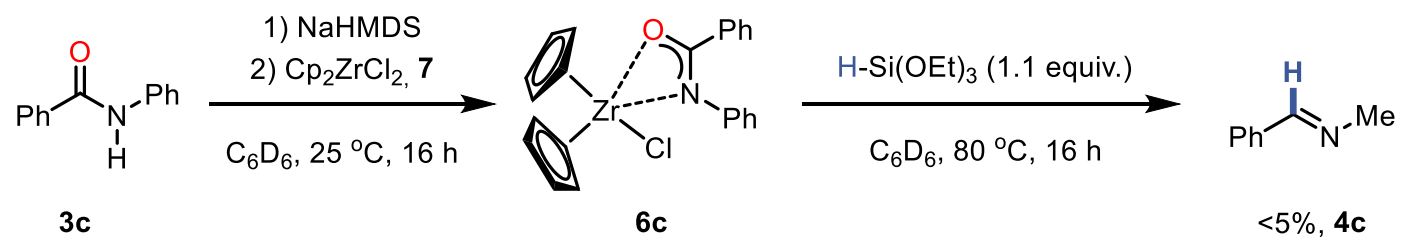

Scheme 3. Investigations of reaction mechanism through stoichiometric control experiments.

A model amidatozirconocene complex $6 \mathrm{c}$ was synthesised from $\mathrm{Cp}_{2} \mathrm{ZrCl}_{2} 7$ and the sodium salt of $\mathbf{3 c}$ following the procedure of Rosenthal and Schafer (Scheme 3B). ${ }^{23}$ When the in situ formed complex $6 \mathrm{c}$ was heated in the presence of one equivalent of $(\mathrm{EtO})_{3} \mathrm{SiH}$, there was no reaction and the formation of the corresponding imine product 4c was not observed. Similarly, using complex 7 as the catalyst under standard catalytic conditions does not convert $\mathbf{3 a}$ to $\mathbf{4 a}$. These results would suggest that complex $\mathbf{1}$ is the only hydride species that reacts directly with the amide and amide derivatives. Therefore, we propose that the only role of $(\mathrm{EtO})_{3} \mathrm{SiH}$ is in the regeneration of 1 from 2 through $\sigma$-bond metathesis of $\mathrm{Si}-\mathrm{H}$ and $\mathrm{Zr}-\mathrm{OR}$. Because the silane does not react directly with the amide derivatives the excellent chemoselectivity of catalyst 1 is preserved from its reported stoichiometric reactivity. ${ }^{18}$ During the course of our investigations, Bayeh-Romero and co-workers described the in situ preparation of $\mathbf{1}$ from dichloride complex 7 and dimethoxy-(methyl)silane (DMMS) in the presence of $\mathrm{Et}_{2} \mathrm{NH}^{2}{ }^{24}$ They then applied this method to the catalytic hydrosilylation of aldehydes 
and ketones. Their mechanistic investigations support the intermediacy of complex 2 and its conversion to 1 in the presence of silane.

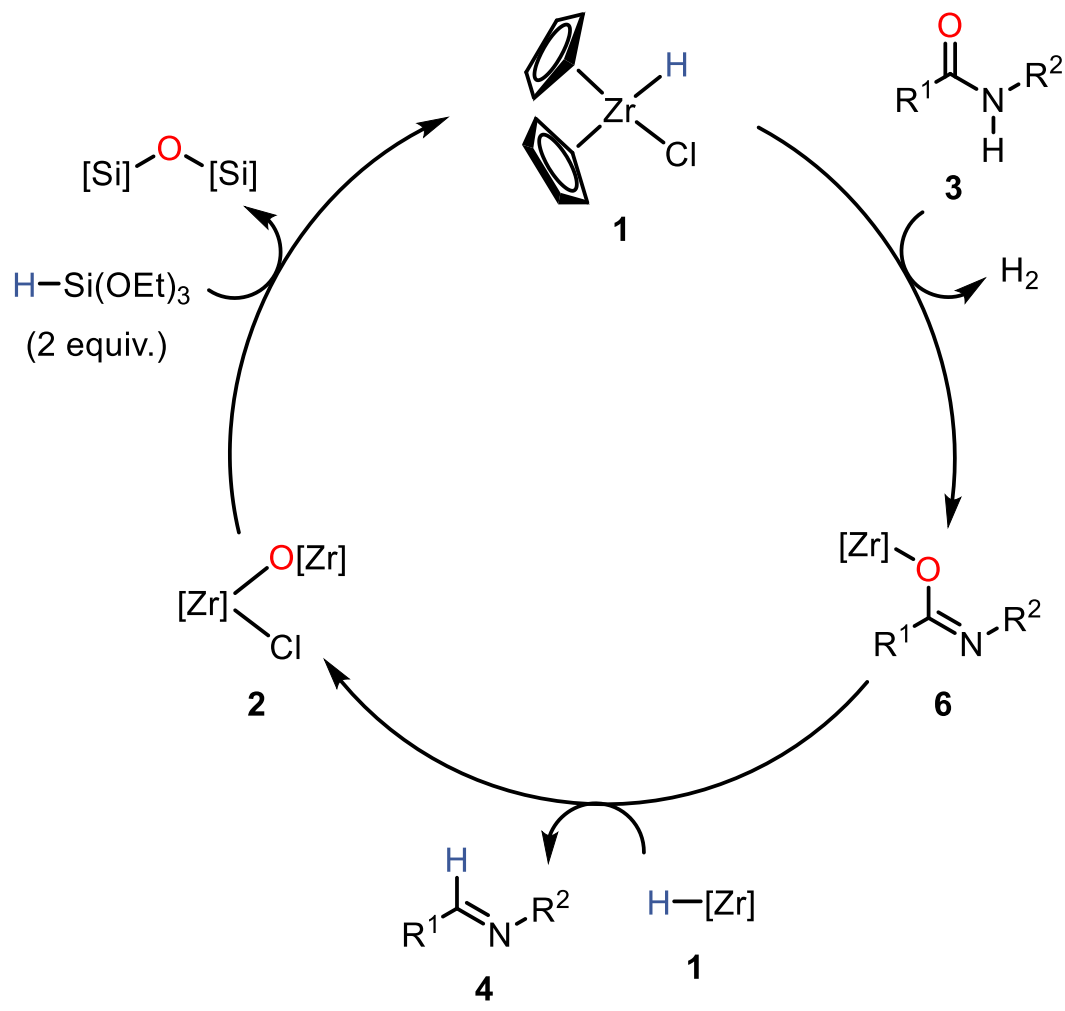

Scheme 4. Proposed catalytic cycle for the Zr-catalysed reduction of secondary amides to imines.

Therefore, we propose that this reaction proceeds via initial dehydrogenative deprotonation of the amide substrate $\mathbf{3}$ to form an amidatozirconocene intermediate $\mathbf{6}$ (Scheme 4). This intermediate undergoes exchange with a second hydride equivalent of $\mathbf{1}$ to form the desired imine product $\mathbf{4}$ and an oxo-bridged zirconocene byproduct $\mathbf{2}$. This species can then react with an equivalent of silane to regenerate the active zirconocene hydride catalyst 1 through $\sigma$-bond metathesis with 2 .

\section{Conclusion}

While the synthesis of valuable imine products by the catalytic reduction of secondary amides is a very appealing transformation, this had previously only been achieved using $\operatorname{Ir}(I)$ catalysts. We have shown that the classical organometallic reagent $\mathbf{1}$ can be used as a earth-abundant metal catalyst, in combination with a hydrosilane, to selectively form imines from secondary amides and avoid overreduction to amines. This catalytic system retains the excellent chemoselectivity and broad functional group tolerance that was observed for the original stoichiometric protocol. We expect that there are many more applications of this chemistry for the selective catalytic reduction of a wide variety of functionalities. 


\title{
Experimental
}

\author{
$\underline{\text { Imine Synthesis }}$
}

General Procedure A:

In a glovebox under a purified argon atmosphere, $(\mathrm{EtO})_{3} \mathrm{SiH}(195 \mu \mathrm{L}, 1.05 \mathrm{mmol})$ was added to a mixture of amide $3(0.5 \mathrm{mmol})$ and $\mathrm{Cp}_{2} \mathrm{Zr}(\mathrm{H}) \mathrm{Cl}(13 \mathrm{mg}, 0.050 \mathrm{mmol})$ in THF $(2 \mathrm{~mL})$ in a sealed round-bottom flask. The reaction was removed from the glovebox and heated at $80^{\circ} \mathrm{C}$ with stirring for $16 \mathrm{~h}$. The solvent was removed under vacuum and the crude reaction mixture was purified by filtration through a short alumina plug (activated, basic, Brockmann I) eluting with hexane $\left(1 \% \mathrm{Et}_{3} \mathrm{~N}\right)$ or a gradient of hexane $\left(1 \% \mathrm{Et}_{3} \mathrm{~N}\right)$ to hexane/EtOAc 9:1 $\left(1 \% \mathrm{Et}_{3} \mathrm{~N}\right)$ to yield the pure imine product 4.

\section{General Procedure B:}

In a glovebox under a purified argon atmosphere, $(\mathrm{EtO})_{3} \mathrm{SiH}(117 \mu \mathrm{L}, 0.63 \mathrm{mmol})$ was added to a mixture of amide $3(0.3 \mathrm{mmol})$ and $\mathrm{Cp}_{2} \mathrm{Zr}(\mathrm{H}) \mathrm{Cl}(7.8 \mathrm{mg}, 0.030 \mathrm{mmol})$ in THF-d8 $(0.5 \mathrm{~mL})$ in a J. Young NMR tube with mesitylene $(20.9 \mu \mathrm{L}, 0.15 \mathrm{mmol})$ as internal standard. The reaction was removed from the glovebox and heated at $80^{\circ} \mathrm{C}$ for $16 \mathrm{~h}$. The reaction mixture was analyzed by ${ }^{1} \mathrm{H}$ NMR spectroscopy and the yield of imine product 4 was determined by integration against the mesitylene signals. The identity of the product was verified by ${ }^{1} \mathrm{H},{ }^{13} \mathrm{C}$ and $\left({ }^{1} \mathrm{H},{ }^{13} \mathrm{C}\right)$ - $\mathrm{HSQC}$ NMR spectroscopic analysis and compared to NMR spectra previously reported in the literature.

\section{Acknowledgements}

For financial support we acknowledge CEA, CNRS, University of Paris-Saclay, European Research Council (ERC consolidator grant agreement no. 818260) and H2020 Sun-to-X project (grant agreement no. 883264).

\section{References}

\footnotetext{
1. Volkov, A.; Tinnis, F.; Slagbrand, T.; Trillo, P.; Adolfsson, H., Chemoselective reduction of carboxamides. Chemical Society Reviews 2016, 45 (24), 6685-6697.

$2 . \quad K a i s e r$, D.; Bauer, A.; Lemmerer, M.; Maulide, N., Amide activation: an emerging tool for chemoselective synthesis. Chemical Society Reviews 2018, 47 (21), 7899-7925.

3. Czerwiński, P. J.; Furman, B., Reductive Functionalization of Amides in Synthesis and for Modification of Bioactive Compounds. Frontiers in Chemistry 2021, 9, 148.

4. Khalimon, A. Y., Deoxygenative hydroboration of carboxamides: a versatile and selective synthetic approach to amines. Dalton Transactions 2021.

5. Blondiaux, E.; Cantat, T., Efficient metal-free hydrosilylation of tertiary, secondary and primary amides to amines. Chemical Communications 2014, 50 (66), 9349-9352.

6. Pelletier, G.; Bechara, W. S.; Charette, A. B., Controlled and Chemoselective Reduction of Secondary Amides. Journal of the American Chemical Society 2010, 132 (37), 12817-12819.

7. Bechara, W. S.; Pelletier, G.; Charette, A. B., Chemoselective synthesis of ketones and ketimines by addition of organometallic reagents to secondary amides. Nature Chemistry 2012, 4 (3), 228-234.

8. $\quad$ Cheng, C.; Brookhart, M., Iridium-Catalyzed Reduction of Secondary Amides to Secondary Amines and Imines by Diethylsilane. Journal of the American Chemical Society 2012, 134 (28), 11304-11307.
} 
9. Motoyama, Y.; Aoki, M.; Takaoka, N.; Aoto, R.; Nagashima, H., Highly efficient synthesis of aldenamines from carboxamides by iridium-catalyzed silane-reduction/dehydration under mild conditions. Chemical Communications 2009, (12), 1574-1576.

10. Ou, W.; Han, F.; Hu, X.-N.; Chen, H.; Huang, P.-Q., Iridium-Catalyzed Reductive Alkylations of Secondary Amides. Angewandte Chemie International Edition 2018, 57 (35), 11354-11358.

11. Chen, D.-H.; Sun, W.-T.; Zhu, C.-J.; Lu, G.-S.; Wu, D.-P.; Wang, A.-E.; Huang, P.-Q., Enantioselective Reductive Cyanation and Phosphonylation of Secondary Amides by Iridium and Chiral Thiourea Sequential Catalysis. Angewandte Chemie International Edition 2021, 60 (16), 8827-8831.

12. Huang, P.-Q.; Ou, W.; Han, F., Chemoselective reductive alkynylation of tertiary amides by Ir and Cu(i) bis-metal sequential catalysis. Chemical Communications 2016, 52 (80), 11967-11970.

13. Ong, D. Y.; Fan, D.; Dixon, D. J.; Chiba, S., Transition-Metal-Free Reductive Functionalization of Tertiary Carboxamides and Lactams for a-Branched Amine Synthesis. Angewandte Chemie International Edition 2020, 59 (29), $11903-11907$.

14. Matheau-Raven, D.; Gabriel, P.; Leitch, J. A.; Almehmadi, Y. A.; Yamazaki, K.; Dixon, D. J., Catalytic Reductive Functionalization of Tertiary Amides using Vaska's Complex: Synthesis of Complex Tertiary Amine Building Blocks and Natural Products. ACS Catalysis 2020, 10 (15), 8880-8897.

15. Schedler, D. J. A.; Godfrey, A. G.; Ganem, B., Reductive deoxygenation by Cp2ZrHCl: Selective formation of imines via zirconation/hydrozirconation of amides. Tetrahedron Letters 1993, 34 (32), 5035-5038.

16. Schedler, D. J. A.; Li, J.; Ganem, B., Reduction of Secondary Carboxamides to Imines. The Journal of Organic Chemistry 1996, 61 (12), 4115-4119.

17. White, J. M.; Tunoori, A. R.; Georg, G. I., A Novel and Expeditious Reduction of Tertiary Amides to Aldehydes Using $\mathrm{Cp} 2 \mathrm{Zr}(\mathrm{H}) \mathrm{Cl}$. Journal of the American Chemical Society 2000, 122 (48), 11995-11996.

18. Spletstoser, J. T.; White, J. M.; Tunoori, A. R.; Georg, G. I., Mild and Selective Hydrozirconation of Amides to Aldehydes Using $\mathrm{Cp} 2 \mathrm{Zr}(\mathrm{H}) \mathrm{Cl}$ : Scope and Mechanistic Insight. Journal of the American Chemical Society 2007, 129 (11), 3408-3419.

19. Han, B.; Zhang, J.; Jiao, H.; Wu, L., Zirconium-hydride-catalyzed site-selective hydroboration of amides for the synthesis of amines: Mechanism, scope, and application. Chinese Journal of Catalysis 2021, 42 (11), $2059-2067$.

20. Ilic, S.; Alherz, A.; Musgrave, C. B.; Glusac, K. D., Thermodynamic and kinetic hydricities of metal-free hydrides. Chemical Society Reviews 2018, 47 (8), 2809-2836.

21. Pouessel, J.; Jacquet, O.; Cantat, T., Pushing Back the Limits of Hydrosilylation: Unprecedented Catalytic Reduction of Organic Ureas to Formamidines. ChemCatChem 2013, 5 (12), 3552-3556.

22. The presence of characteristic alkene $\mathrm{C}-\mathrm{H}$ signals in the ${ }^{1} \mathrm{H}$ NMR $(\delta 5.87(\mathrm{dd}, \mathrm{J}=17.5,1.0 \mathrm{~Hz}, 1 \mathrm{H}), 5.29(\mathrm{dd}, \mathrm{J}=10.9$, $1.1 \mathrm{~Hz}, 1 \mathrm{H})$ ) suggest hydrosilylation of the alkyne although these products were not fully characterised. This reactivity is well established for Schwartz's reagent: Hart, D. W.; Blackburn, T. F.; Schwartz, J., Hydrozirconation. III. Stereospecific and regioselective functionalization of alkylacetylenes via vinylzirconium(IV) intermediates. Journal of the American Chemical Society 1975, $97(3), 679-680$.

23. Haehnel, M.; Priebe, J. B.; Yim, J. C.-H.; Spannenberg, A.; Brückner, A.; Schafer, L. L.; Rosenthal, U., Four-Membered Heterometallacyclic d0 and d1 Complexes of Group 4 Metallocenes with Amidato Ligands. Chemistry - A European Journal 2014, 20 (25), 7752-7758.

24. Kehner, R. A.; Hewitt, M. C.; Bayeh-Romero, L., Expanding Zirconocene Hydride Catalysis: In Situ Generation and Turnover of ZrH Catalysts Enabling Catalytic Carbonyl Reductions. ACS Catalysis 2022, 1758-1763. 